\title{
Stage II Eyelid Carcinoma AJCC v8
}

National Cancer Institute

\section{Source}

National Cancer Institute. Stage II Eyelid Carcinoma A/CC v8. NCI Thesaurus. Code C140519.

Stage II includes: IIA: T2b-c, T3, N0, M0; IIB: T4, N0, M0. T2b: Tumor measuring more than $10 \mathrm{~mm}$ but $20 \mathrm{~mm}$ or less in greatest dimension with invasion of the tarsal plate or eyelid margin. T2c: Tumor measuring more than $10 \mathrm{~mm}$ but $20 \mathrm{~mm}$ or less in greatest dimension involving the full thickness of the eyelid. T3: Tumor measuring more than 20 $\mathrm{mm}$ but $30 \mathrm{~mm}$ or less in greatest dimension. T4: Any eyelid carcinoma invading adjacent ocular, orbital, or facial structures. N0: No evidence of lymph node involvement. M0: No distant metastasis. (AJCC 8th ed.) 